\title{
Development of Damage Rate and Damage Index Functions for Brick-nogging and Wooden Buildings in 2012 Thabeikkyin Earthquake
}

\author{
Nan Pawt Sai Awar, Dr. Kyaw Moe Aung
}

\begin{abstract}
A large earthquake had occurred on 11 November 2012, and many houses are severely damaged by the strong ground motion. For every earthquake, structures need to be surveyed in terms of building types, vulnerability and the degrees of damages. Buildings with different types of structures are damaged with various damage patterns and damage grades. So field investigation is important and it should be made as soon as possible after a high intensity earthquake occurred. In this paper, damage patterns and damage grades are proposed for brick-nogging and wooden buildings to classify building damaged without many difficulties. This paper also discusses the damage rate function to estimate the percentage of buildings damaged in different ground motions and the damage index function to know the damage degree of individual building.
\end{abstract}

Keywords - field investigation, damage patterns, grades, damage rate function, damage index function.

\section{INTRODUCTION}

Myanmar is one of the earthquake prone countries. As it is situated on the boundary of the Alpine-Himalayan earthquake belt, there is always the seismic risk. In addition to this, the Sagaing fault is one of the great strike-slip faults of Southeast Asia, bisecting Myanmar from North to South. It is also the major right-lateral fault between the Sunda and Burma plates with the fault slip rate of $18 \mathrm{~mm} / \mathrm{yr}$. So Myanmar often suffered from earthquakes that sometimes caused great loss of human lives and damage to many historical buildings.

Thabeikkyin earthquake (Mw 6.8) has occurred $25 \mathrm{~km}$ away from Thabeikkyin Township, Mandalay Region in Myanmar. According to the trip report from the Myanmar Earthquake Committee [6], it happened because of the sudden movement of the Sagaing fault on 7:42 A.M. (local time) of November 11, 2012 and epicenter at $95.883^{\circ} \mathrm{E}, 23.014^{\circ} \mathrm{N}, 9.9 \mathrm{~km}$ (depth), that is $72.42 \mathrm{~km}$ far from Northern part of Shwebo Township, Sagaing District, Myanmar.

Structures need to be surveyed in terms of different types, the vulnerability of typical structures and the different scales of damaged within each building type. It is necessary to record the various types of buildings that were damaged to a lesser or greater degree. In this study, typical damage patterns due to earthquake and damage grades (heavy, moderate and slight)

Nan Pawt Sai Awar is a Ph.D student in Department of Civil Engineering, Mandalay Technological University.

Dr. Kyaw Moe Aung is an associate professor in Department of Civil Engineering, Mandalay Technological University. are proposed for single and two storey brick-nogging and wooden buildings by using field investigation and the recorded photographs. Therefore, it can easily be classified the damage degrees of each building without many difficulties even non professional. From this, damage rate function and damage index function are developed to evaluate the percentage of buildings damaged and the damage degree of individual building in different ground motions.

\section{SURVEYED AREAS}

The affected areas of 2012 Thabeikkyin earthquake are Mandalay, Inwa, Amarapura, Sagaing, Thabeikkyin, Kyauk Myaung and Singu in Mandalay District and Sagaing District. Especially Thabeikkyin Township, Kyauk Myaung Township and Singu Township had severe damaged. Field investigations have been carried out Twin Nge village, Ma Lae village, Thabeikkyin Town, Kyauk Myaung Town, Ma Lar village and Singu Town. These are the most affected areas during earthquake.

During field survey, the structural types of buildings were classified as R.C, brick-nogging, masonry and wooden buildings. We made preliminary field survey on 29 May and 11 June with some master students from Department of Civil Engineering, Mandalay Technological University in 2014. During this survey, we made visit to the General Administrative Office in the Thabeikkyin Township and collected the recorded photographs and the damage statistics data such as the numbers of buildings that partially collapsed and totally damaged in this township. Fig. 1 and Fig. 2 show the location of epicenter and intensity of earthquake affected areas.

According to the preliminary investigation and recorded photographs, it can be seen that the most damaged structural type of building was brick-nogging (wooden frame with brick walls). Wooden building was the second most damaged structural type. Other structural types of buildings such as R.C buildings and masonry buildings also damaged but they are not so much in number compared with brick-nogging and wooden. They can also be classified as residential buildings and non-residential buildings such as governmental offices, hospital (including dispensaries), school and religious buildings by the usage of buildings. Fig.3, Fig.4 and Fig. 5 show some damage buildings after Thabeikkyin Earthquake. 


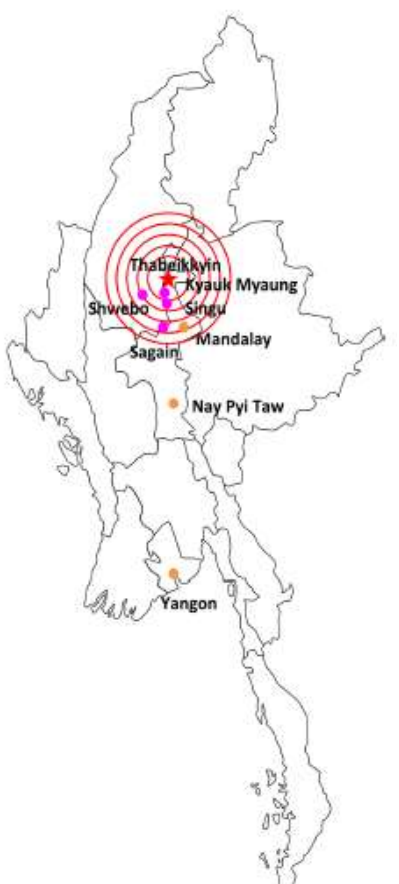

Fig.1 Location of epicenter and main affected areas of the earthquake

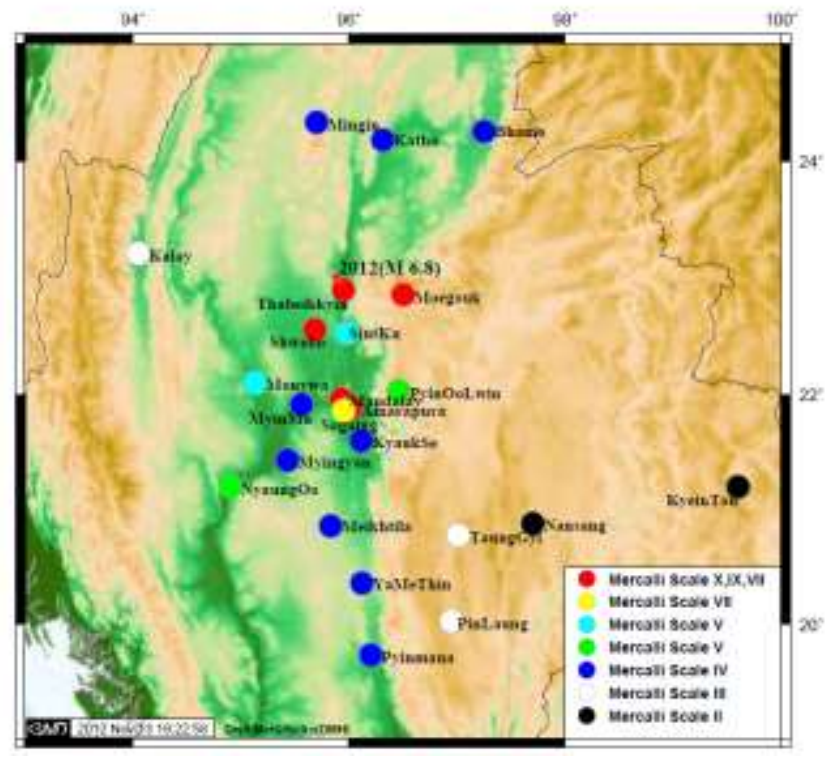

Source: Department of Meteorology and Hydrology, Myanmar Fig. 2 Intensity scales of earthquake affected areas

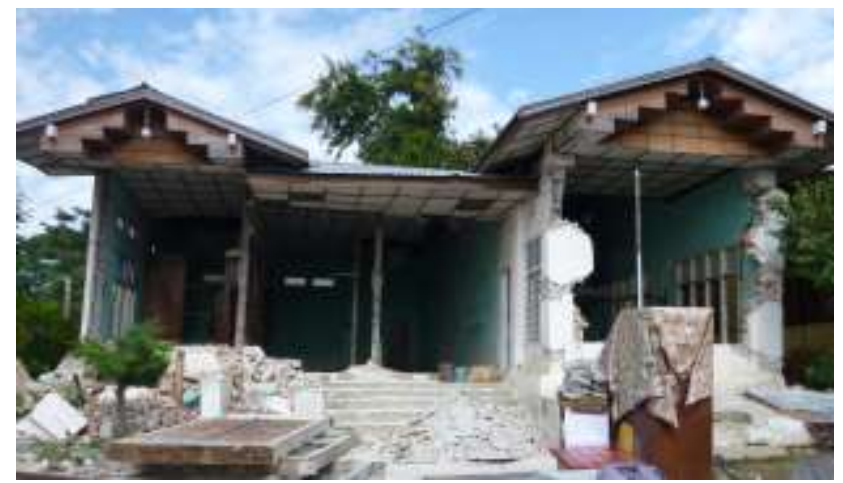

Fig. 3 Collapse of masonry walls in single-storey governmental office

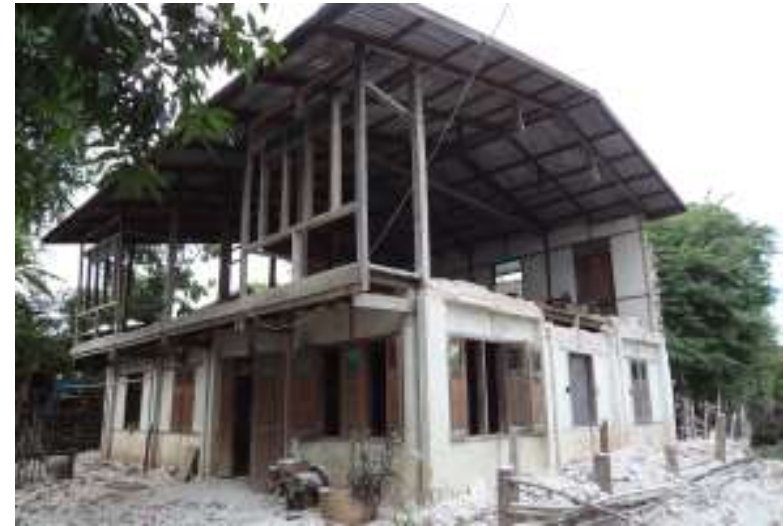

Fig.4 Collapse of masonry walls in two-storied residential building

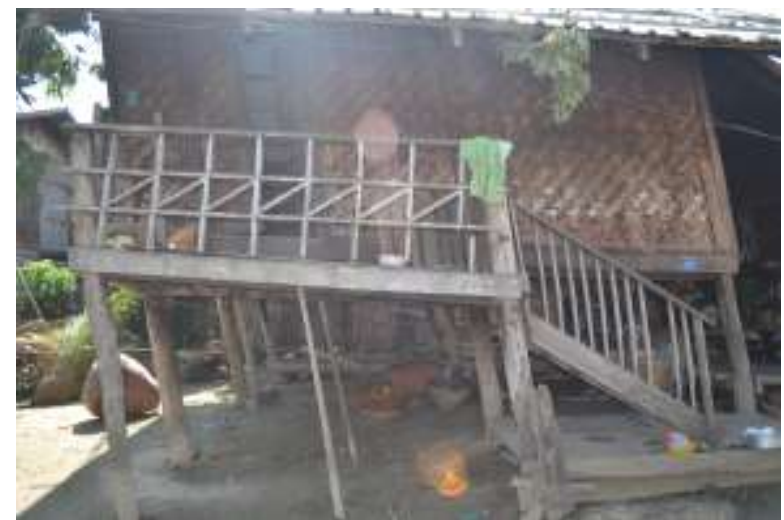

Fig. 5 Failure of veranda in wooden residential building

\section{Damage Patterns AND GRADES}

During earthquake, masonry dwelling houses generally shattered though portions of the walls were left standing sometimes. In some extreme cases, two-storied houses appeared to have been literally hurled to the ground, falling almost flat in low heaps bricks, plaster and splintered beams shattered. Foundations of heavy column were cracked and shifted. In some areas, masonry buildings, all of which were damaged, and some almost completely destroyed. The brick foundations of the timber posts supporting the houses were badly cracked horizontally [1]. In this study, damage patterns of brick-nogging buildings and wooden buildings are categorized by paying attention to damages of buildings on the basis of recorded photographs in the 2012 Thabeikkyin earthquake and responses of local people in the questionnaire survey. The damages are also arranged for three damage grades (slight, moderate and heavy) to classify the damage levels based on EMS-98 [3]. Each damage grade depends on the range of damage suffered from each building. The damage pattern of each building is studied on the facts such as the location of damaged members, the range of damage in these members and the structural type according to the recorded photograph. Damages were classified to single storey brick-nogging building into five types of damage patterns in the previous study [10]. We modify it in this study. Table I illustrates typical damage patterns and damage grades of brick-nogging buildings and wooden buildings. 
TABLE I: DAMAge PATteRnS AND DAMAGE GRADES OF BRICK-NOGGING AND \begin{tabular}{lcc}
\multicolumn{3}{c}{ WOODEN BUILDINGS } \\
\cline { 2 - 4 } Structural types & \multicolumn{3}{c}{ Damage grades } \\
\cline { 2 - 4 } \\
Brick-nogging (one \\
storey)
\end{tabular}

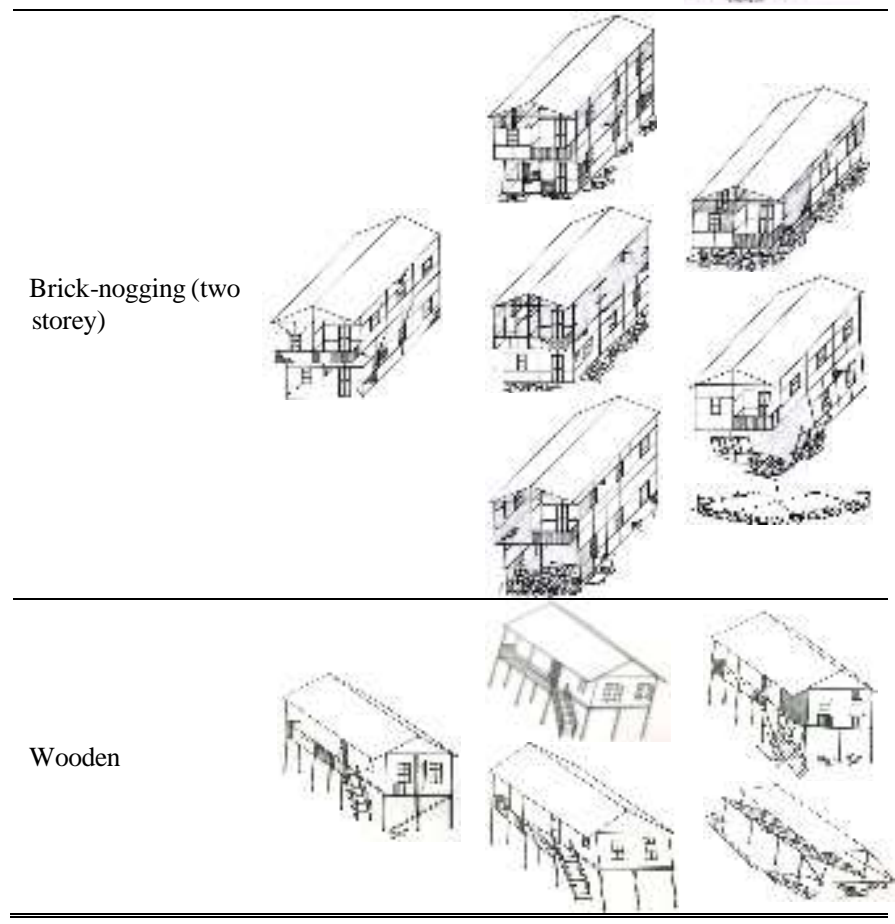

IV. Damage Rate Function And Damage Index FunCtion

\section{A. Damage Rate Function}

Damage rate function, which is a sort of vulnerability function describing the percentage of elements damaged in the area, is available for roughly estimating the number of damages to regional elements at risk, especially building, at the level of administrative pre-countermeasures [7]. In this study, the seismic intensity of each study area is based on questionnaire-based seismic intensity (QMSK). Table II and Table III show the number of buildings for brick-nogging buildings and wooden buildings in selected study areas with respect to the structural type for three damage grades: slight, moderate, and heavy.
TABLE II: SUMMARY OF BUILDING DAMAGE FOR BRICK-NOGGING BUILDINGS

\begin{tabular}{lrrrrr}
\hline \multirow{2}{*}{ Location } & \multicolumn{5}{c}{ Number of Buildings } \\
\cline { 2 - 6 } & No Damage & Slight & Moderate & Heavy & Total \\
\hline Kyauk Myaung & 13 & 68 & 56 & 6 & 143 \\
Singu & 32 & 95 & 64 & 17 & 208 \\
Malar and Makauk & 6 & 56 & 35 & 14 & 111 \\
Thabeikkyin & 6 & 6 & 21 & 14 & 47 \\
Twin Nge & 7 & 35 & 80 & 10 & 132 \\
Malae and Pzigyi & 3 & 15 & 48 & 44 & 110 \\
\hline \hline
\end{tabular}

TABLE III: SUMMARY OF BUILDING DAMAGE FOR WOODEN BUILDINGS

\begin{tabular}{lrrrrr}
\hline \multirow{2}{*}{ Location } & \multicolumn{5}{c}{ Number of Buildings } \\
\cline { 2 - 6 } & No Damage & Slight & Moderate & Heavy & Total \\
\hline Kyauk Myaung & 298 & 51 & 12 & 5 & 366 \\
Singu & 148 & 127 & 18 & 6 & 299 \\
Malar and Makauk & 304 & 102 & 2 & 8 & 416 \\
Thabeikkyin & 195 & 37 & 27 & 7 & 266 \\
Twin Nge & 207 & 53 & 45 & 29 & 388 \\
Malae and Pzigyi & 195 & 37 & 27 & 7 & 334 \\
\hline \hline
\end{tabular}

The curves of the damage rate functions of brick-nogging buildings and wooden buildings are constructed using the damage ratio of buildings in each location and the estimated MSK seismic intensity by questionnaire survey. The function is generally described with the following cumulative normal distribution function.

$$
F(x)=\phi\left(\frac{x-\mu}{\sigma}\right)
$$

where, $F(x)$ means damage rate in damaged area, $\phi$ is the standard normal distribution and $\mu$ and $\sigma$ are the mean and standard deviation of $\mathrm{x}$. The two parameters of the distributions, $\mu$ and $\sigma$ are determined by the least square method on normal probability plotting paper.

Fig. 6 and Fig. 7 show the damage rate curves for brick-nogging buildings and wooden buildings.

TABLE IV: PARAMETERS OF PROPOSED DAMAGE RATE FUNCTIONS

\begin{tabular}{lcccc}
\hline \hline \multirow{2}{*}{ Damage Grades } & \multicolumn{2}{c}{ For Brick-nogging } & \multicolumn{2}{c}{ For Wooden } \\
\cline { 2 - 5 } & $\begin{array}{c}\text { Average } \\
(\boldsymbol{\mu})\end{array}$ & $\begin{array}{c}\text { Stand. } \\
\text { Dev. }(\boldsymbol{\sigma})\end{array}$ & $\begin{array}{c}\text { Average } \\
(\boldsymbol{\mu})\end{array}$ & $\begin{array}{c}\text { Stand. Dev. } \\
(\boldsymbol{\sigma})\end{array}$ \\
\hline Heavy & 7.6 & 0.72 & 7.5 & 1.0 \\
Moderate+ & 6.6 & 0.8 & 6.85 & 1.0 \\
Slight+ & 5.45 & 0.8 & 5.8 & 0.9 \\
\hline \hline
\end{tabular}

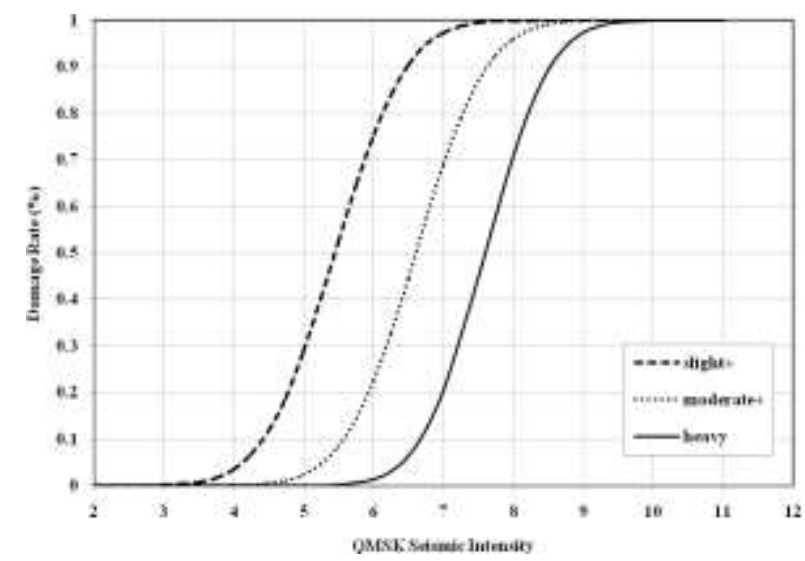

Fig. 6 Damage rate function of brick-nogging buildings 


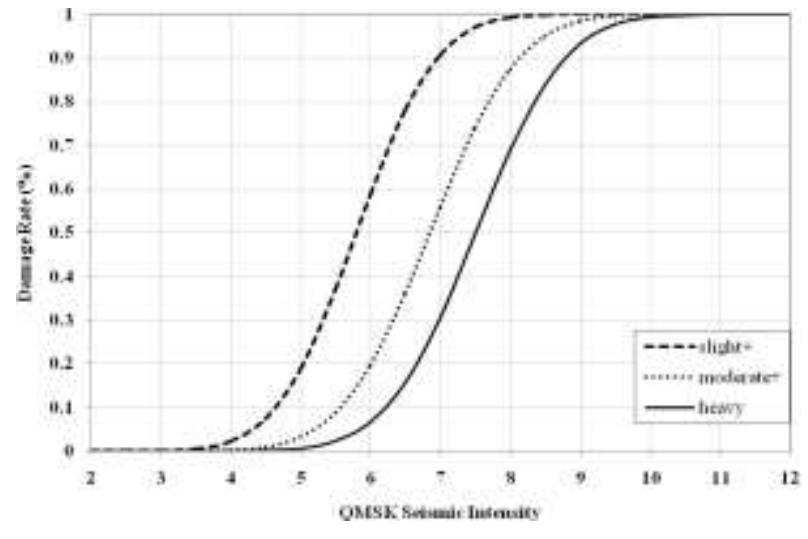

Fig. 7 Damage rate function of wooden buildings

\section{B. Damage Index Function}

The damage index function is a function capable of calculating the damage state (i.e. damage index) of individual building under a certain ground motion severity represented by the intensity or peak ground velocity. Damage index function can express the seismic structural damage state of individual building. S. Okada and N. Takai [5] gave the numerical scale of damage degree defining from 0 (no damage) to 1.0 (total collapse) with some visualized damage patterns of buildings so as to help field investigation to classify building damaged without a gross error [7]. Table $\mathrm{V}$ shows the comparison between various damage grades. The damage grades of EMS-98 and the damage grades are compared in this study. For the damage index, the damage index scales are used from S. Okada and N. Takai [5].

TABLE V: COMPARISON BETWEEN VARIOUS DAMAGE GRADES

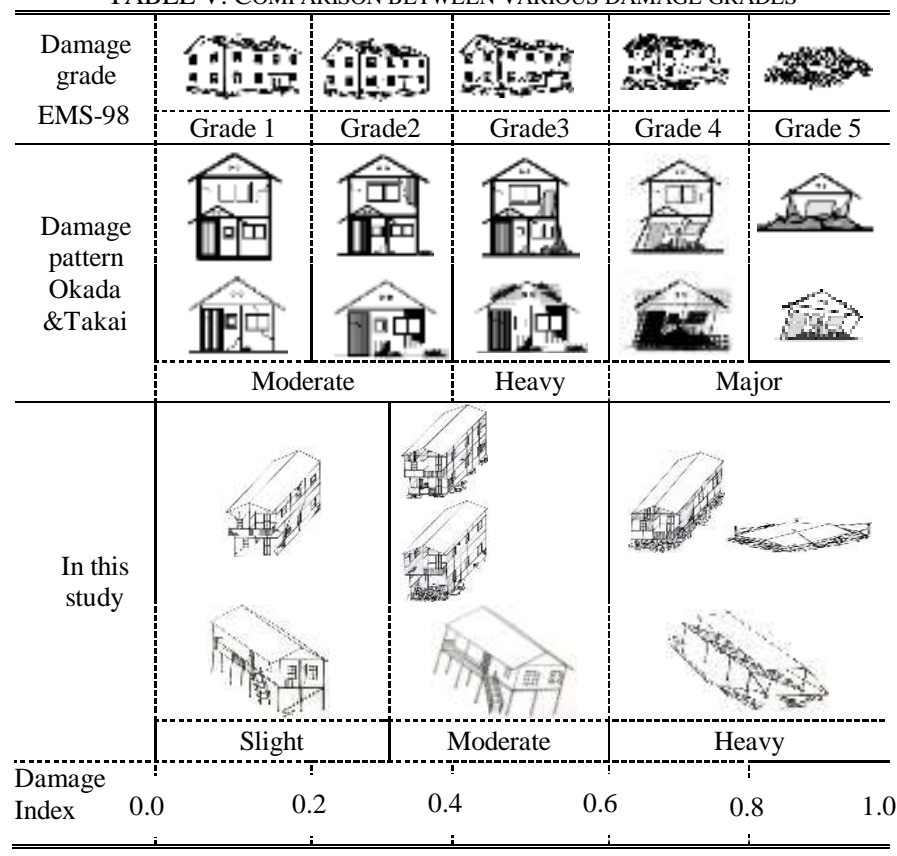

In this study, the damage indices are specified as slight $(0.0$ to 0.3 ), moderate (0.3 to 0.6 ) and heavy (0.6 to 1.0$)$. The damage index function is the inverse function of the damage rate function [7]. The seismic intensity affecting the damage grades can be obtained at arbitrary damage rates $(1 \%, 20 \%$, $40 \%, 60 \%, 80 \%$ and $99 \%$ ) in this study. The damage index functions are obtained by fitting the following cumulative probability distribution with the Weibull density function.

$$
F(x)=1-e^{-\left(\frac{x}{\eta}\right)^{\beta}}
$$

where, $F(x)$ means damage index, $x$ is an index of seismic intensity, $\beta$ and $\eta$ are parameters of the Weibull distribution. These two parameters of the distribution are determined by Weibull distribution plotting paper.

Table VI describe the parameters of damage index function for brick-nogging buildings and wooden buildings. Fig. 8 and Fig. 9 show the damage index functions of brick-nogging buildings and wooden buildings.

TABLE VI: PARAMETERS OF PROPOSED DAMAGE INDEX FUNCTIONS

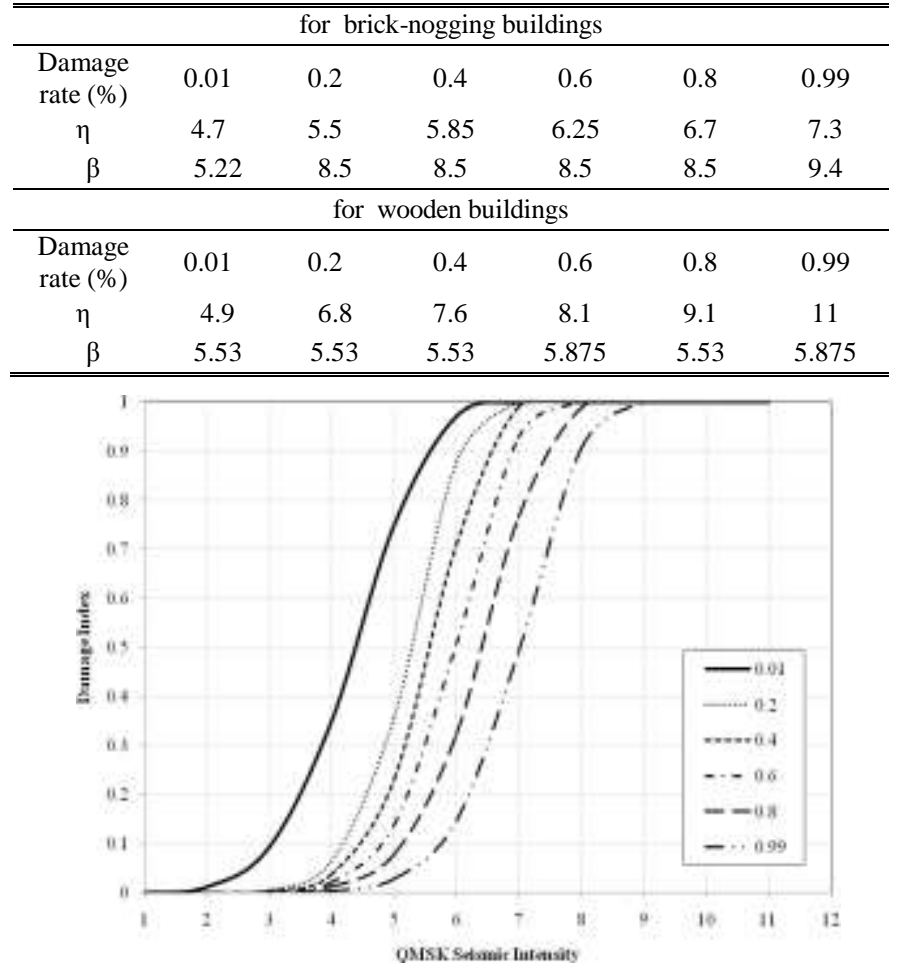

Fig. 8 Damage index function of brick-nogging buildings

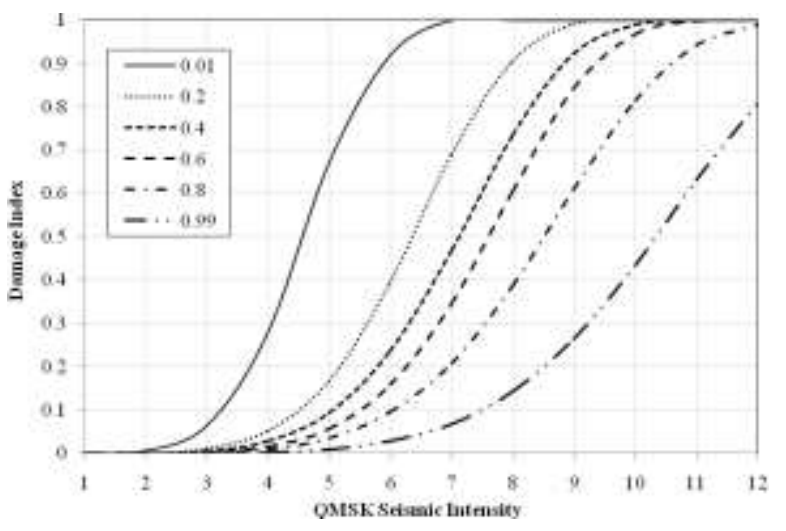

Fig. 9 Damage index function of wooden buildings 


\section{CONCLUSION}

In this paper, the damage patterns of brick-nogging and wooden buildings could be categorized by paying attention to damages of buildings on the basis of recorded photographs in the 2012 Thabeikkyin earthquake. Damage grades are also specified with damage patterns based on EMS-98. According to the damage patterns and damage grades, the damage levels of buildings can easily be classified without difficulties. From this study, the damage rate functions describing the percentage of damage in a region are obtained to estimate the probability of percentage of damaged buildings for an assumed seismic intensity. The damage index functions capable of calculating the damage state of each building are also proposed under a certain ground motion severity. The same functions for other structural types of buildings can be obtained by following the above methods.

\section{ACKNOWLEDGMENT}

The authors would like to express their deepest gratitude to Prof. Junji Kiyono from Kyoto University and Prof. Maki Koyama from Gifu University, Japan, for their valuable guidance and valuable suggestions. Special thanks go to Dr. Aye Mya Cho, Associate Professor, Department of Civil Engineering, Mandalay Technological University for her valuable guidance and approval to submit as a requirement for their research. The authors also take to mention thank to all of teachers and stuffs of Department of Civil Engineering, Mandalay Technological University. Finally, the authors thank to all who helped them with necessary assistance for this paper.

\section{REFERENCES}

[1] H. H. Aung, "Preliminary report on the 2012 Thabeikkyin earthquake in northern Myanmar", Tech Digest Quarterly Magazine Vol. 5/ No. 3 April, 2013, pp. 54.

[2] Geotechnical Earthquake Engineering Research Unit, "Trip Report: The 6.8 Magnitude of Earthquake in the Union of Myanmar", 2012.

[3] G. Grunthal, "European Macroseismic Scale 1998", Cahiers du Centre Europeen de Geodynamiqueet de Seismologie, Volume 15, 1998.

[4] Japanese Meteorological Agency, "Summary of Tables explaining the JMA Seismic Intensity Scale", Website: http://www.jma.go.jp/.

[5] S. Okada and N. Takai, "Classifications of structural types and damage patterns of buildings for earthquake field investigation", Proceedings of the 12th World Conference on Earthquake Engineering, Auckland, New Zeeland, Paper no. 0705, 2000.

[6] SEEDS-Asia Myanmar, "The 2012 Thabeikkyin Earthquake (GLIDE: EQ-2012-000190-MMR) Situation Report 1”, 2012.

[7] S. Okada and N. Takai, "Damage index functions of wooden buildings and reinforced buildings for seismic risk management", Proceedings of the 13th World Conference on Earthquake Engineering, Vancouver, B.C., Canada, Paper no. 727, 2004.

[8] O. Murao and F. Yamazaki (1999a), "Development of Fragility Curves for Buildings based on Damage Data due to the Hyogoken-Nanbu Earthquake", Proceedings of Asian-Pacific Symposium on Structural Reliability and its Applications, pp.259-269.

[9] A. Fallahi, P. Teymourzadeh, M. Miyagima, T, Tobita and B. Alaghebandian, "Statistical Study to Determine JMA Earthquake Intensity by Questionnaire Survey in 2003 Bam (Iran) Earthquake", The 14th World Conference on Earthquake Engineering, October 12-17, 2008, Beijing, China.

[10] P. S. Awar, K. M. Aung, J. Kiyono and M. Koyama, "Damage Patterns of Typical Local Houses in the 2012 Thabeikkyin Earthquake", in the
Proceedings of the 5th International Conference of the Science and Engineering, December 29-30, 2014, Yangon, Myanmar.

[11] H. Murakami, "Estimation of MSK Seismic Intensity by Questionnaire Method, A Comprehensive Survey of the 26 January 2001 Earthquake (Mw7.7) in the State of Gujarat, India"\|, Report by the Research Team Supported by the Grant-in-aid for Specially Promoted Research, p. 64-70, 2001.

[12] J. Miyakoshi, Y. Hayashi, K. Tamura, and N. Fukuwa, "Damage ratio functions of building using damage data of the 1995 Hyogo-Ken Nanbu Earthquake", Proceedings of the 7thInternational Conference on the Structural Safety and Reliability 1: 349-354, 1998.

[13] Z. Z. Nwe, A. M. Cho, M. Koyama and J. Kiyono, "Estimation of MSK Seismic Intensity for Thabeikkyin Earthquake by Questionnaire Survey", in the Proceedings of the 5th International Conference of the Science and Engineering, December 29-30, 2014, Yangon, Myanmar.

[14] Y. Wang, K. Sieh, T. Aung, S. Min, S. N. Khaing and S. T. Tun (2010), "Earthquakes and slip rate of the southern Sagaing fault: insights from an offset ancient fort wall, lower Burma (Myanmar)", Geophysical Journal International, 185: 49-64, doi: 10.1111/j.1365-246X.2010.04918.x.

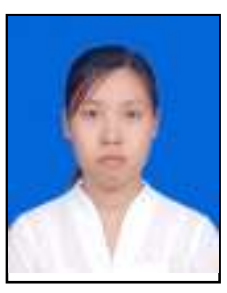

Nan Pawt Sai Awar is a Ph.D student and doing research in earthquake engineering field in Department of Civil Engineering, Mandalay Technological University. The author has got Bachelor Degree in 2006 and Master Degree in 2010. 